\title{
Injúrias de quatro espécies de percevejos pentatomídeos em plântulas de milho
}

\author{
Injuries of four species of stink bugs to corn seedlings
}

\section{Margarida Flores Roza- Gomes ${ }^{\mathrm{I}}$ José Roberto Salvadori ${ }^{\mathrm{II}}$ Paulo Roberto Valle da Silva Pereira ${ }^{\mathrm{III}}$ Antônio Ricardo PanizziII}

\section{RESUMO}

\begin{abstract}
Neste estudo, foram caracterizadas as injúrias causadas pelos percevejos Dichelops furcatus (F.), Nezara viridula (L.) e Euschistus heros (F.), em comparação com D. melacanthus (Dallas), em plântulas de milho (Zea mays L.). O experimento foi realizado em vasos, em ambiente de telado, em delineamento inteiramente casualizado, com cinco tratamentos (infestação com percevejos de quatro espécies e testemunha, sem infestação) em oito repetições. Na fase vegetativa do milho (estádio $V_{1}$ até $V_{3}$ ), D. melacanthus, na densidade de um adulto/planta, provocou redução na altura, no número de folhas expandidas, na massa seca das raízes e provocou injúrias no cartucho elou enrolamento das folhas centrais da planta. D. furcatus, E. heros e $\boldsymbol{N}$. viridula causaram injúrias, porém, em intensidades diferentes. As injúrias causadas por D. furcatus $e \boldsymbol{N}$. viridula foram semelhantes na forma e intensidade às de D. melacanthus e as injúrias causadas por $\boldsymbol{E}$. heros foram menos intensas que as dos demais percevejos estudados.
\end{abstract}

Palavras-chave: Nezara viridula, Euschistus heros, Dichelops melacanthus, Dichelops furcatus, Pentatomidae, Zea mays.

\section{ABSTRACT}

Injuries caused by the stink bugs Dichelops furcatus (F.), Nezara viridula (L.) and Euschistus heros (F.), compared with Dichelops melacanthus (Dallas), to corn (Zea mays L.) seedlings were studied. The experiment was conducted in a greenhouse in a completely randomized design with five treatments (four species of stink bugs and control, without infestation) using eight replications. In the vegetative stage $\left(V_{l}\right.$ to $\left.V_{3}\right) \boldsymbol{D}$. melacanthus, at the density of one adult/plant, caused reduction in height, in the number of expanded leaves, in root dry matter, and caused injuries and winding of the central leaves. D. furcatus, $\boldsymbol{E}$. heros and $\boldsymbol{N}$. viridula caused injuries, but at different intensities. Injuries caused by $\boldsymbol{D}$. furcatus and $N$. viridula were similar in intensity to those by $D$. melacanthus and the injuries caused by $\boldsymbol{E}$. heros were less intense than those of the other species.

Key words: Nezara viridula, Euschistus heros, Dichelops melacanthus, Dichelops furcatus, Pentatomidae, Zea mays.

\section{INTRODUÇÃO}

Espécies de percevejos fitófagos da família Pentatomidae (Hemiptera, Heteroptera), vulgarmente denominados fede-fedes, são consideradas pragas importantes em plantas de diferentes lavouras, especialmente soja (PANIZZI \& SLANSKY JÚNIOR, 1985; CORRÊA-FERREIRA\& PANIZZI, 1999; PANIZZI et al., 2000). Geralmente, esses percevejos atacam os órgãos reprodutivos das plantas (PANIZZI \& SLANSKY JÚNIOR, 1985; PANIZZI et al., 2000; CORRÊA-FERREIRA\&AZEVEDO, 2002), condição na qual são considerados pragas principais em soja, pragas eventuais em trigo (MAIA, 1973; LINK \& PANICHI,

'Departamento de Ciências Exatas e da Terra, Universidade do Oeste de Santa Catarina (UNOESC), 89900-000, São Miguel do Oeste, SC, Brasil. E-mail: margarida.gomes@unoesc.edu.br. Autor para correspondência.

"Faculdade de Agronomia e Medicina Veterinária (FAMV), Programa de Pós-graduação em Agronomia, Universidade de Passo Fundo (UPF), Passo Fundo, RS, Brasil.

II'Embrapa Trigo, Passo Fundo, RS, Brasil. 
1979) e, recentemente, em milho (BIANCO et al., 2001; BIANCO, 2004). Nesse contexto, destacam-se as espécies Nezara viridula (L.), Piezodorus guildinii (West.) e Euschistus heros (F.) como pragas de soja (GAZZONI et al., 1981; CORRÊA-FERREIRA \& PANIZZI, 1999; HOFFMANN-CAMPO et al., 2000). $N$. viridula e Thyanta perditor (F.) em trigo (GASSEN, 1984) e Dichelops melacanthus (Dallas) e Dichelops furcatus (F.) em milho (PANIZZI \& CHOCOROSQUI, 2000; BIANCO et al., 2001; BIANCO, 2004; ), embora poucos estudos tenham sido realizados para essa última cultura.

Devido a alterações nos processos de produção de grãos no Brasil, principalmente à adoção do sistema de plantio direto na palha, a expansão da fronteira agrícola e o cultivo das áreas durante o ano todo, têm ocorrido modificações na composição da entomofauna associada às culturas e na importância relativa das espécies fitófagas (SALVADORI et al., 2002). Isso favoreceu a sobrevivência de pentatomídeos polífagos, cuja população pode aumentar a ponto de causar danos em diversas culturas (PANIZZI, 1997; CHOCOROSQUI, 2001; CHOCOROSQUI \& PANIZZI, 2004) como, por exemplo, no milho.

Nas últimas duas décadas, espécies de Dichelops, consideradas pragas secundárias de frutificações de soja, passaram a atacar principalmente plântulas de milho, fato que ocorreu no início do desenvolvimento dessas culturas, que é a fase crítica para o adequado estabelecimento da lavoura. Apesar da presença de Dichelops spp. em plantas cultivadas já ser conhecida (PANIZZI \& SLANSKY JÚNIOR, 1985; LINK \& GRAZIA, 1987; CHOCOROSQUI, 2001), registros de prejuízos econômicos no Brasil aconteceram na década de 1990 e, a partir daí, tornaram-se frequentes e esse inseto passou a ser considerado praga inicial do milho, trigo e soja (BIANCO \& NISHIMURA, 1998; GOMEZ, 1998, GASSEN, 2002; SALVADORI et al., 2002; CHOCOROSQUI \& PANIZZI, 2004).

As espécies $\boldsymbol{D}$. furcatus e D. melacanthus têm sido observadas em lavouras de milho danificando plantas jovens, causando o amarelecimento e lesões punctiformes nas folhas (CORRÊA-FERREIRA \& PANIZZI, 1999; BIANCO, 2005). Os danos são ocasionados pela alimentação próxima ao colo das plântulas, causando injúrias típicas, e, à medida que as folhas se desenvolvem, as lesões aumentam, as plantas de milho ficam deformadas, amareladas e com o desenvolvimento comprometido (ÁVILA \& PANIZZI, 1995). Ataques severos podem ocasionar a morte de plântulas, com a consequente redução do estande da lavoura (PANIZZI \& CHOCOROSQUI, 2000).
N. viridula tem sido citado como praga esporádica em plântulas de milho (GASSEN, 1996; CRUZ et al., 1997), mas seu elevado grau de polifagia e ampla distribuição geográfica lhe conferem a condição de praga potencial nessa cultura. Da mesma forma, o aumento na ocorrência de $\boldsymbol{E}$. heros em soja no Brasil (FERNANDES et al., 1990; CIVIDANES \& PARRA 1994; PEREIRA \& SALVADORI, 2008), espécie também polífaga, tem sido visto como uma ameaça para outras plantas de lavoura, como o milho.

Embora para D. melacanthus existam informações sobre a caracterização das injúrias que causam em milho, isso não está bem esclarecido para outras espécies de percevejos pentatomídeos que têm ocorrido na cultura. Esse tipo de conhecimento é importante para fazer diagnósticos mais precisos com relação ao agente causador das injúrias. Por essa razão, foi conduzido este trabalho com o objetivo de caracterizar as injúrias causadas pelos percevejos $\boldsymbol{D}$. furcatus, $\boldsymbol{N}$. viridula $\mathrm{E} \boldsymbol{E}$. heros, em comparação com D. melacanthus, em plântulas de milho.

\section{MATERIAL E MÉTODOS}

O experimento foi desenvolvido na sede da Embrapa Trigo, em Passo Fundo, RS, em telado, exposto às condições climáticas ambientais, onde a temperatura e a umidade não foram controladas, no período de novembro a dezembro de 2008.

Odelineamento experimental foi inteiramente casualizado com cinco tratamentos (infestação artificial com D. melacanthus, D. furcatus, E. heros e N. viridula e testemunha -sem infestação) e oito repetições. A unidade experimental constou de um vaso $(22 \mathrm{~cm}$ de diâmetro com capacidade de $15 \mathrm{~L}$ ) onde foram cultivadas cinco plantas de milho. O genótipo utilizado foi o híbrido Pioneer '32R21' e a semeadura foi realizada em 03/11/2008.

Os insetos utilizados, exceto os da espécie D. furcatus, foram provenientes de criação mantida no Laboratório de Entomologia da Embrapa Trigo, a partir de indivíduos coletados a campo, em 2007. Devido à dificuldade de criação, os indivíduos de $\boldsymbol{D}$. furcatus foram obtidos a campo, uma semana antes da infestação. Para todas as espécies, os insetos foram submetidos a jejum de $12 \mathrm{~h}$ antes da infestação.

A infestação foi realizada aos seis dias após a emergência e mantida por 14 dias, até quando as plantas apresentavam em torno $15 \mathrm{~cm}$ de altura, o que correspondeu aos estádios $\mathrm{V}_{1}$ (1 a folha desenvolvida) e $V_{3}$ (três folhas desenvolvidas), da escala de RITCHIE \& HANWAY (1989). A densidade de infestação foi de cinco percevejos adultos (três fêmeas e dois machos) 
de cada espécie por vaso, numa proporção de um percevejo adulto por planta.

Os percevejos permaneceram no milho por um período de 14 dias. Nesse período, todas as unidades experimentais (inclusive as testemunhas) permaneceram protegidas por gaiolas (sacos de tecido do tipo voile, com $70 \mathrm{~cm}$ de altura e $40 \mathrm{~cm}$ de largura, suspensos por armação de arame), presas em torno da boca do vaso com o auxílio de elástico para evitar a fuga dos percevejos. A cada dois dias foram realizadas avaliações para verificar o comportamento dos insetos em relação à alimentação e para substituição dos mortos.

A avaliação foi realizada 10 dias após a retirada dos insetos das plantas, com o objetivo de que se pudesse visualizar melhor as possíveis injúrias decorrentes da ação dos percevejos nas plantas. Essa avaliação teve a finalidade de caracterizar sinais/ sintomas da ação dos insetos nas plantas, medir a altura da planta do solo até $\mathrm{o}$ anel da última folha que estava dobrando e o número de folhas expandidas com anel formado. Também, realizou-se a caracterização das injúrias com base na escala de notas adotada por BIANCO et al. (2001), BIANCO (2004) e PIONEER (2010), com as seguintes adaptações: a nota 0 (zero) foi atribuída para plantas isentas de injúrias; 1 (um) para folhas com pontuações, sem redução de porte; 2 (dois) para plantas com leve injúria no cartucho (parcialmente enrolado), com redução de porte; 3 (três) para planta com cartucho encharutado (preso) ou planta perfilhada e; 4 (quatro) para plantas com cartucho seco ou morto.

Vinte dias após a retirada dos insetos, finalizou-se o ensaio com a coleta das plantas inteiras. Para tanto, os vasos foram virados visando a separar as raízes do solo, sem danificá-las. As plantas foram lavadas e distendidas individualmente para secagem em estufa (a $65^{\circ} \mathrm{C}$ durante seis dias) e posterior avaliação da massa seca da parte aérea e das raízes.
Os dados (altura, número de folhas, massa seca da parte aérea e das raízes das plantas e o grau de injúria causado pelos insetos) foram submetidos à análise da variância e as médias comparadas pelo teste de Tukey $(\mathrm{P}>0,05)$.

\section{RESULTADOS E DISCUSSÃO}

Os resultados da infestação das quatro espécies de percevejos (D. melacanthus, D. furcatus, E. heros e $N$. viridula $)$ desde o estádio $\mathrm{V}_{1}\left(1^{a}\right.$ folha desenvolvida, aos seis dias após a emergência) até o estádio de $\mathrm{V}_{3}$ (três folhas desenvolvidas) da cultura do milho indicaram efeitos significativos sobre as variáveis analisadas (Tabela 1).

A altura das plantas do solo até o anel da última folha que estava dobrando foi afetada significativamente pela atividade alimentar de $\boldsymbol{D}$. melacanthus, com redução de 29,3\% comparada com a testemunha. As demais espécies de percevejo não causaram efeito significativo nessa variável (Tabela 1). Isso pode ter ocorrido devido à possível diferença em relação à toxidez na saliva de $D$. melacanthus em relação às demais. Porém, essa hipótese precisa ser ainda avaliada em pesquisas futuras que estudem o grau de toxicidade e/ou enzimas presentes na saliva de cada uma das diferentes espécies de percevejos.

Resultado semelhante foi observado quanto ao número de folhas expandidas, já que D. melacanthus ocasionou redução significativa no número de folhas $(13,3 \%)$; as demais espécies de percevejos se igualaram à testemunha (Tabela 1).

Quando foi analisada a intensidade das injúrias, através das notas de 0 a 4 , todas as espécies causaram algum tipo de injúria, diferindo da testemunha, livre de insetos (Tabela 1). As plantas apresentaram perfurações nas folhas, redução de altura e danos no

Tabela 1 - Efeito da infestação de quatro espécies de percevejos em plântulas de milho, em telado (média \pm EP). Passo Fundo, RS, 2008.

\begin{tabular}{|c|c|c|c|c|c|}
\hline \multirow{2}{*}{ Espécie ${ }^{(1)}$} & \multirow{2}{*}{ Altura anel $(\mathrm{cm})$} & \multirow{2}{*}{$\mathrm{N}^{\mathrm{o}}$ folhas expandidas } & \multirow{2}{*}{ Injúrias ${ }^{(2)}$} & \multicolumn{2}{|c|}{ 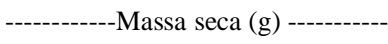 } \\
\hline & & & & Parte aérea & Raízes \\
\hline Testemunha & $9,2 \pm 0,3 \mathrm{a}$ & $3,0 \pm 0,0 \mathrm{a}$ & $0,0 \pm 0,0 \mathrm{a}$ & $4,4 \pm 0,2 \mathrm{ab}$ & $3,8 \pm 0,2 \mathrm{a}$ \\
\hline D. melacanthus & $6,5 \pm 0,2 b$ & $2,6 \pm 0,1 b$ & $2,8 \pm 0,1 \mathrm{c}$ & $3,6 \pm 0,2 b$ & $2,9 \pm 0,1 b$ \\
\hline D. furcatus & $8,1 \pm 0,3 \mathrm{a}$ & $2,7 \pm 0,1 \mathrm{ab}$ & $2,7 \pm 0,1 \mathrm{c}$ & $4,6 \pm 0,2 \mathrm{a}$ & $3,8 \pm 0,2 \mathrm{a}$ \\
\hline E. heros & $8,2 \pm 0,4 \mathrm{a}$ & $2,9 \pm 0,1 \mathrm{ab}$ & $1,0 \pm 0,1 b$ & $4,1 \pm 0,1 \mathrm{ab}$ & $3,6 \pm 0,1 \mathrm{a}$ \\
\hline N. viridula & $8,3 \pm 0,4 a$ & $2,8 \pm 0,1 \mathrm{ab}$ & $2,4 \pm 0,3 c$ & $4,1 \pm 0,3 \mathrm{ab}$ & $3,5 \pm 0,1 \mathrm{a}$ \\
\hline CV \% & 11,5 & 8,1 & 30,1 & 13,0 & 11,5 \\
\hline
\end{tabular}

Médias seguidas da mesma letra, na coluna, não diferem entre si pelo teste de Tukey $(\mathrm{P}>0,05)$.

(1) Infestação na proporção de 1 percevejo/plântula (entre os estádios $\mathrm{V}_{1} \mathrm{e} \mathrm{V}$ ), durante 14 dias.

(2) Escala de notas para planta: $0=$ isenta de injúria; $1=$ folhas com pontuações, sem redução de porte; $2=1$ leve injúria no cartucho (parcialmente enrolado), com redução de porte; 3 = cartucho encharutado (preso) ou planta perfilhada; $4=$ cartucho seco ou morto. 
cartucho (parcial ou totalmente enrolado, seco ou morto). As quatro espécies estudadas causaram injúrias e, provavelmente (devido às características apresentadas nas folhas), se alimentaram das plântulas de milho, diferindo na intensidade dos sinais que provocaram. D. melacanthus, $D$. furcatus e $N$. viridula causaram injúrias entre os graus 2 (caracterizado na escala de notas como "enrolamento parcial do cartucho e redução do porte da planta") e 3 (caracterizado na escala de notas como "cartucho encharutado/preso ou planta perfilhada"). Neste experimento, não foi constatado perfilhamento, como resposta das plantas ao ataque dos percevejos para nenhuma das espécies avaliadas. As plantas que receberam nota 3 apresentaram apenas cartucho encharutado/preso. No caso de $\boldsymbol{D}$. furcatus e de $\boldsymbol{N}$. viridula, porém, a injúria possivelmente esteve mais associada ao enrolamento do cartucho do que ao efeito sobre o porte da planta, uma vez que, quando efetivamente quantificada, a altura de planta não foi reduzida significativamente por essas espécies (Tabela 1). Já $\boldsymbol{E}$. heros, embora tenha provocado perfurações, estas foram menos evidentes em relação às provocadas pelas outras três espécies, e também não reduziu o porte das plantas. Nesse sentido, as pontuações provocadas por $\boldsymbol{E}$. heros podem ser interpretadas como picadas de prova ou permitem especular sobre a possibilidade de que $\boldsymbol{E}$. heros possa se alimentar efetivamente em plântulas de milho, o que necessita ser devidamente investigado no futuro.

Considerando-se as notas de injúrias, as plantas que apresentaram maiores valores e sinais mais intensos foram as que estiveram submetidas aos percevejos D. melacanthus e D. furcatus, seguidas por aquelas infestadas por $\boldsymbol{N}$. viridula. Com nota superior a 2, as plantas infestadas por essas espécies apresentaram injúrias no cartucho e também redução de altura.

Resultados semelhantes a esses, como perfurações, injúrias no cartucho, encharutamento e redução de altura, foram relatados por PANIZZI \& CHOCOROSQUI (2000) para D. melacanthus, em plântulas de milho.

Tanto a massa seca da parte aérea como a das raízes foi afetada significativamente pelos tratamentos (Tabela 1). O maior índice de redução de massa seca da parte área das plantas foi de 18,2\%, causado por D. melacanthus, embora essa diferença não tenha sido significativa em relação à testemunha. O fato de D. melacanthus e de D. furcatus diferirem entre si para a variável massa seca da parte aérea sugere que essas espécies podem ter algum fator diferencial tóxico na saliva, que justificam a realização de estudos para a sua investigação.

Embora as plantas apresentassem sinais visíveis de dano também para $D$. furcatus, $N$. viridula e $\boldsymbol{E}$ heros, de forma menos evidente para essa última espécie, estas espécies não diferiram da testemunha quanto à massa seca da parte aérea e radicular. Essa diferença só ocorreu para $\boldsymbol{D}$. melacanthus para a massa seca radicular, cuja infestação resultou em uma redução de $23,7 \%$ nesta variável.

D. furcatus, E heros e N. viridula não ocasionaram redução na altura das plantas, no número de folhas expandidas, na massa seca aérea e radicular das plantas de milho, quando comparados com as plantas sem infestação, apesar de provocarem sinais de injúria característicos e semelhantes aos descritos por ÁVILA \& PANIZZI (1995), CHOCOROSQUI (2001) e BIANCO (2005) para a espécie D. melacanthus.

Para D. melacanthus, perdas no rendimento de grãos do milho têm sido associadas principalmente à redução no desenvolvimento da planta, encharutamento de folhas e diminuição da massa seca aérea (ÁVILA \& PANIZZI, 1995; CHOCOROSQUI, 2001; BIANCO, 2005). Pesquisas complementares devem ser desenvolvidas para estabelecer a relação entre a intensidade de injúrias ocasionadas pelas espécies $\boldsymbol{D}$. furcatus, $\boldsymbol{E}$ heros e $\boldsymbol{N}$. viridula e sua relação com a redução da produção em milho. Neste experimento, a intensidade das injúrias foi tão elevada que, provavelmente, afetaria a produção de grãos, fato este, apenas especulativo e que sugere estudos futuros, já que, neste trabalho, a produção não foi avaliada.

\section{CONCLUSÃO}

Em plântulas de milho sob infestação de um percevejo por planta, durante quatorze dias (desde o estádio $V_{1}$ até o estádio $V_{3}$ ), constatou-se que:

D. melacanthus reduz a altura da planta, o número de folhas expandidas, a massa seca das raízes e provoca injúrias no cartucho e/ou enrolamento das folhas centrais da planta;

D. furcatus, $E$ heros e $N$. viridula também causam injúrias, porém, em intensidades diferentes; sendo as causadas por $\boldsymbol{E}$. heros as menos intensas.

As injúrias causadas por $\boldsymbol{D}$. furcatus e $\boldsymbol{N}$. viridula são semelhantes em tipo e intensidade às de D. melacanthus.

\section{AGRADECIMENTOS}

Ao técnico agrícola Egídio Sbrissa, da Embrapa Trigo de Passo Fundo, RS, pelo auxílio na realização dos experimentos. Aos estagiários do Laboratório de Entomologia, pelo auxílio na manutenção da criação dos insetos. À Embrapa Trigo, pela disponibilização de recursos humanos, laboratórios, área 
experimental e demais dependências e à Universidade de Passo Fundo, pela concessão de bolsa de estudo ao primeiro autor, via Programa de Pós-graduação em Agronomia, Faculdade de Agronomia e Medicina Veterinária (FAMV), Universidade de Passo Fundo (UPF).

\section{REFERÊNCIAS}

ÁVILA, C.J.; PANIZZI, A.R. Ocurrence and damage by Dichelops (Neodichelops) melachantus (Dallas) (Heteroptera: Pentatomidae) on corn. An Soc Entomol. Jaboticabal- SP. v.24, p.193-194, 1995.

BIANCO, R.; NISHIMURA, M. Efeito do tratamento de sementes de milho no controle do percevejo barriga verde (Dichelops furcatus). In: CONGRESSO BRASILEIRO DE ENTOMOLOGIA, 17., 1998, Rio de Janeiro, RJ. Resumos... Rio de Janeiro: Sociedade Entomológica do Brasil, 1998. p.203.

BIANCO, R. et al. Avaliação de cultivares de milho quanto ao dano do percevejo barriga verde, Dichelops spp. In: SEMINÁRIO NACIONAL DE MILHO SAFRINHA, 2001, Londrina, PR. Anais... Londrina-PR: Iapar, 2001. p 21.

BIANCO, R. Nível de dano e período crítico do milho ao ataque do percevejo barriga verde (Dichelops melacanthus). In: CONGRESSO NACIONAL DE MILHO E SORGO, 25., 2004, Cuiabá, MT. Anais... Cuibá-MT: Associação Brasileira de Milho e Sorgo, 2004. p.172.

BIANCO, R. Manejo de pragas do milho em plantio direto. In: INSTITUTO BIOLÓGICO DE SÃO PAULO. (Org.), 2005 , Campinas, SP. Encontro de fitossanidade de grãos. Campinas: Emopi, 2005. p.8-17.

CORRÊA-FERREIRA, B.S.; PANIZZI, A.R. Percevejos da soja e seu manejo. Londrina: Embrapa-CNPSo, 1999. 45p. (Circular técnica, 24).

CORRÊA-FERREIRA, B.S.; AZEVEDO, J. Soybean seed damage by different species of stink bugs. Agric For Entomol v.4, p.145-150, 2002. Disponível em: <http://onlinelibrary.wiley.com/ doi/10.1111/afe.2002.4.issue-2/issuetoc>. Acesso em: $10 \mathrm{fev}$. 2010. doi: 10.1046/j.1461-9563.2002.00136.x.

CHOCOROSQUI, V.R. Bioecologia de Dichelops (Diceraeus) melacanthus (Dallas, 1851) (Heteroptera: Pentatomidae), danos e controle em soja, milho e trigo no norte do Paraná. 2001. 160f. Tese (Doutorado em Ciências Biológicas) - Universidade Federal do Paraná, Curitiba, PR.

CHOCOROSQUI, V.R.; PANIZZI, A.R. Impact of cultivation systems on Dichelops melacanthus (Dallas) (Heteroptera: Pentatomidae) population and damage and its chemical control on wheat. Neotrop Entomol, v.33, n.4, p.487-492, 2004. Disponível em: <http://www.scielo.br/scielo.php?pid=S1519 566X2004000400014\&script $=$ sci_arttext $>$. Acesso em: 10 fev. 2010. doi:10.1590/S1519-566X2004000400014.

CIVIDANES, F.J.; PARRA, J.R.P. Zoneamento ecológico de Nezara viridula (L.), Piezodorus guildinii (West.) e Euschistus heros (Fabr.) (Heteroptera: Pentatomidae) em quatro estados produtores de soja do Brasil. An Soc Entomol, v.23, p.219$226,1994$.

CRUZ, I. et al. Manual de identificação de pragas da cultura do milho. Sete Lagoas: Embrapa/CNPMS, 1997. 667p.

FERNANDES, O.A. et al. Manejo integrado de pragas e nematóides. Jaboticabal: FUNEP, 1990. 253p.

GASSEN, D.N. Insetos associados à cultura do trigo no Brasil. Passo Fundo: Embrapa- CNPT, 1984. 39p. (Circular Técnica, 3).
GASSEN, D.N. Manejo de pragas associadas à cultura do milho. Passo Fundo: Embrapa- Aldeia Norte, 1996. 134p.

GASSEN, D. O percevejo barriga-verde em plântulas de milho. Passo Fundo: Cooplantio, 2002. 134p.

GAZZONI, D.L et al. Manejo de pragas da soja. Londrina: Embrapa- CNPSo, 1981. 44p. (Circular Técnica, 5).

GOMEZ, S.A. Controle químico do percevejo Dichelops (Neodichelops) melacanthus (Dallas) (Heteroptera: Pentatomidae) na cultura do milho safrinha. Dourados: EMBRAPA-CPAO, 1998. 5p. (Comunicado Técnico, 44).

GRAZIA, J. Revisão do gênero Dichelops Spinola, 1837 (Heteroptera: Pentatomidae, Pentatomini). Iheringia, Série Zoológica, v.53, p.3-119, 1978.

HOFFMANN-CAMPO, C.B. et al. Pragas da soja no Brasil e seu manejo integrado. Londrina: Embrapa Soja, 2000. 70p. (Circular Técnica, 30).

LINK, D.; GRAZIA, J. Pentatomídeos da região central do Rio Grande do Sul (Heteroptera). An Soc Entomol, v.16, n.1, p.115-129, 1987

LINK, D.; PANICHI, J.V.A. Efeitos do ataque de Nezara viridula (L.) (Hemiptera: Pentatomidae) em trigo. Rev Cen Cienc Rur, v.9, p.265-271, 1979.

MAIA, N.G. Ocorrência do percevejo da soja, Nezara viridula (L.,1758) em espigas de trigo no Rio Grande do Sul. Agronomia Sulriograndense, v.9, p.241-243, 1973.

PANIZZI, A.R. Entomofauna changes with soybean expansion in Brazil. In: NAPOMPETH, B. (Ed.). Proceedings World Soybean Research Conference. Bangkok: Kasetsar University, 1997. p.166-168. 581p.

PANIZZI, A.R. et al. Stink bugs (Pentatomidae). In: SCHAEFER, C.W.; PANIZZI, A.R. (Ed.). Heteroptera of economic importance. Boca Raton, Florida: CRC, 2000. p.432-434.

PANIZZI, A.R.; CHOCOROSQUI, V.R. Os percevejos inimigos. A Granja, n.616, p.40-42, Porto Alegre-RS, 2000.

PANIZZI, A.R.; SLANSKY JR, F. Review of phytophagous pentatomids (Hemiptera: Pentatomidae) associated with soybean in the Americas. Florida Entomologist, v.68, n.1, p.184-214, 1985.

PEREIRA, P.R.V. da S.; SALVADORI, J.R. Aspectos populacionais de percevejos fitófagos ocorrendo na cultura da soja (Hemiptera: Pentatomidae) em duas áreas do norte do Rio Grande do Sul. Passo Fundo: Embrapa Trigo, 2008. 10p. (Comunicado técnico online, 253). Disponível em: <http://www.cnpt.embrapa.br/biblio/co/ p_co253.pdf $>$. Acessado em: 10 jan. 2010.

PIONEER. Herculex I e o Tratamento de Sementes Industrial - Controle em dose máxima. In: SELEME, R. Manejo do milho. Santa Cruz do Sul/RS, 2010. p.6-7. (Comunicado Técnico, 07).

RITCHIE, S.; HANWAY, J.J. How a corn plant develops. Ames, Iowa: Iowa State University of Science and Technology, Cooperative Extension Service, 1989. (Special Report n.48).

SALVADORI, J.R. et al. Pragas-de-solo: evolução e manejo. Revista Cultivar Grandes Culturas. Pelotas-RS, n.44, p.1822, 2002. 